\title{
Com a voz enrouquecida ou considerações sobre a presença de Camões no último capítulo de O crime do padre Amaro, de Eça de Queirós
}

\section{With a rough voice or considerations on the presence of Camões in the final chapter of The crime of father Amaro, by Eça de Queirós}

\author{
Ceila Maria Ferreira* \\ Universidade Federal Fluminense, Niterói, RJ, Brasil
}

\begin{abstract}
Resumo: Esta é uma versão, com poucas modificações, da palestra que foi apresentada durante o Colóquio Um Dia de Camões 8, no Instituto de Letras da UFF. Trata-se de um trabalho sobre a atualidade de Os Lusíadas. Também fizemos considerações sobre a presença de Camões no último capítulo de $O$ crime do padre Amaro, obra que teve três versões, duas delas autorais, e que trouxe e traz ao público leitor o nome e um relato da Comuna de Paris, num exercício do que mais tarde Walter Benjamin chamou de "escovar a história a contrapelo". Tal trabalho também versa sobre a importância da Crítica Textual para a preservação e divulgação do patrimônio cultural em forma de textos escritos, assim como sobre a importância dessa disciplina para os Estudos de Língua e de Literatura.
\end{abstract}

Palavras-chave: Crítica textual. Literatura. Cânone literário. Transmissão textual.

\begin{abstract}
This is a slightly modified version of the talk given during the One Day for Camões 8 colloquium at the Institute of Letters, Federal Fluminense University, Brazil, on the present-day relevance of Os Lusiadas [The Lusiads]. It also offers some reflections on the presence of Camões in the final chapter of $O$ crime do padre Amaro [The crime of father Amaro], a work that exists in three version, two of which were authorial, bringing to readers' attention the name and an account of the Paris Commune, in an exercise in what Walter Benjamin would later call "brushing history against the grain." The work also discusses the importance of textual criticism for the preservation and communication of cultural heritage in the form of writings, as well as the importance of this discipline to studies of language and literature.
\end{abstract}

Keywords: Textual criticism. Literature. Literary canon. Textual transmission.

\footnotetext{
* Professora de Crítica Textual lotada no Departamento de Ciências da Linguagem do Instituto de Letras da UFF, Niterói, Rio de Janeiro, Brasil. Coordenadora do Labec-UFF. Bolsista de Produtividade em Pesquisa 2 do CNPq. Escritora ligada ao Mulherio das Letras Rio; ceilamaria@hotmail.com.
} 


\section{INTRODUÇÃO}

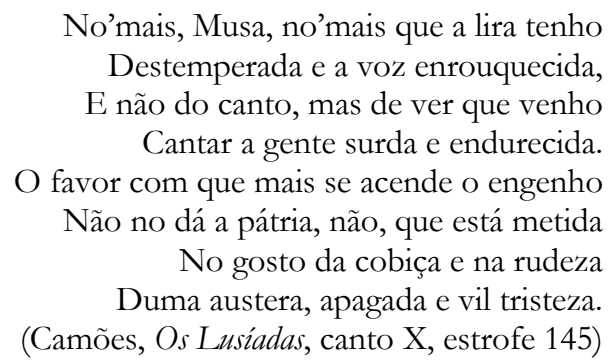

Fizemos questão de iniciar este texto, que teve uma de suas versões apresentada como palestra, no Colóquio Um Dia de Camões 8, organizado por Luís Maffei, com uma determinada estrofe de um famoso Poema. Tal evento contribuiu e contribui, temos certeza, para trazer, aos dias de hoje, a presença rememorada e a palavra do Poeta, o nome dele já um poema de tão belo, musical e luminoso, Luís Vaz de Camões, porque o que estamos vivendo, na atualidade, se assemelha e muito com o que é cantado na estrofe 145 de Os Lusíadas. Se não fosse pela linguagem solene, característica do gênero épico, pareceria que estávamos falando do Brasil da atualidade. Mas, de certa maneira, estamos, pois Camões faz parte da nossa história, da história da humanidade. Além disso, ainda não conseguimos construir, apesar de vivermos no século XXI, um mundo de justiça e de bem-estar para todas e todos. Hoje, parece, para várias pessoas, justiça e bem-estar social é algo que, com o fortalecimento do neoliberalismo, do capitalismo financeiro, ainda mais com o governo do Brasil, hoje, governo de características e de práticas fascistas, estamos longe, muito longe e talvez, conforme o que é transmitido por uma mídia comprometida com o que Jessé Souza chamou de elite do atraso, nunca alcancemos. Então, para algumas pessoas, já cansadas de tantos nãos e desesperançadas, é melhor deixar para lá. Mas as palavras de uma ou de um Poeta têm a força de nos despertar a atenção a respeito das potencialidades da espécie humana seja para o mal, seja para o bem, entendendo, aqui, mal e bem como conceitos que não estão imunes à historicidade.

No caso das epopeias, conforme Francisco da Silveira Bueno (1960, p. 72):

[...] há muito pequeno lugar para a psicologia. Os personagens são todos iguais pela altivez do caráter, pelo denodo e coragem de seus atos, pela lealdade e franqueza de suas ações. Os adversários, ao contrário, só apresentam defeitos, covardia, traição, mesquinhez de temperamento, falsos e perjuros.[...]

Contudo, em Os Lusíadas, o Poeta faz críticas a Portugal de sua época, não se eximindo, inclusive, de dirigi-las ao clero, o que também foi objeto de comentário de Francisco da Silveira Bueno (1960, p. 34). Aqui destacamos os dois últimos versos da estrofe 150, Canto X, da referida obra de Camões, em que podemos ler: "Que o bom religioso verdadeiro/ Glória vã não pretende nem dinheiro.” (Camoões, 1960, p. 757). Vale salientar que o Poeta não se furtou de escrever tais versos num momento em que a Igreja estava extremamente ligada ao poder temporal e que a obra, que havia, segundo a tradição, sido salva, pelo próprio Camões, em um naufrágio, devia passar pela censura do Santo Ofício.

As críticas que o Poeta dirige a seus contemporâneos, como as que citamos no início deste texto, soam muito atuais a nós, brasileiras e brasileiros, sob o governo Bolsonaro, sobretudo, quando tentamos estabelecer um diálogo com pessoas que mais 
se assemelham à "gente surda e endurecida" referidas por Camões. Além disso, a fala do Velho do Restelo, aquele " C'um saber só de experiências feito" (Camões, 1960, p. 380), no Canto IV, é eivada de críticas à empresa dos "descobrimentos" marítimos, o que também pode ser entendido como uma construção de uma brecha para que o Poeta dê voz ao contraditório, o que acaba funcionando, para parte do público leitor, como um escovar a história a contrapelo, num sentido aproximado ao dado por Walter Benjamin, em Sobre o conceito da história, nas palavras traduzidas por Sérgio Paulo Rouanet (Benjamin, 2012, p. 245), uma obra também escrita num momento extremamente sombrio da história da humanidade, a Segunda Guerra Mundial. E digo também, pois o tempo dos "descobrimentos" foi um tempo de genocídio de imenso contingente de povos originários nas terras que, a partir da chegada de europeus, receberam o nome de Américas e a América Latina, ainda hoje, está com suas veias abertas. Até quando?

Voltando a Camões e à atualidade do grande Poeta lusitano, Harold Bloom, crítico literário norte-americano, recentemente falecido, tinha, em parte, razão quando disse, em Gênios, os 100 autores mais criativos da história da literatura, obra em que inclui Camões, Machado de Assis, Eça de Queirós e Fernando Pessoa, que: “[...] o mundo descrito por Camões ainda é o nosso, conquanto Portugal já não seja uma potência ultramarina e o Brasil seja independente. [...]" (Bloom, 2003, p. 528). Vale ressaltar que escrevi que o referido crítico literário norte-americano tinha em parte razão, pois o Brasil vem, cada vez mais, perdendo o que podemos entender por independência.

Lembramos ainda com Marc Bloch, professor que participou da Resistência Francesa e que, em 1944, foi fuzilado por nazistas, que: "Nossa arte, nossos monumentos literários estão carregados dos ecos do passado [...]." (Bloch, 2001, p. 42) e, numa outra passagem de Apologia da História on o oficio de historiador diz que: "[...] a ignorância do passado não se limita a prejudicar a compreensão do presente; compromete, no presente, a própria ação.” (Bloch, 2001, p. 63).

Sim, é preciso ler Camões, não só Os Lusiadas, como também a lírica camoniana, e suas palavras chegam a nós a partir do trabalho de tipógrafos, editores, docentes, escritores, escritoras, críticos e críticas textuais, literários, tradutores, mas sobretudo pelo trabalho do Poeta, que escreveu aquelas páginas, apesar da grande dificuldade em que viveu. Inclusive morreu pobre e seu corpo foi atirado a uma vala comum, envolvido em um lençol, como podemos ler em Silveira Bueno (1960, p. 20):

\begin{abstract}
São obscuros os últimos quatro anos da vida de Camões. Nada de novo publicou e na peste aparecida, novamente em 1579, foi o cantor do Gama uma das suas vítimas. É tradição que um de seus protetores, D. Francisco de Portugal ou D. Manuel, tio deste, enviou um lençol para amortalhar o mais alto cantor que as Tágides haviam inspirado. Em que dia teria falecido? Não se sabe: alguns aventam a hipótese de ter sido a 10 de junho de 1580. [...]
\end{abstract}

\title{
2 Crítica Textual e a Escola Camoniana
}

Em relação à Crítica Textual, é reconhecida a importância da Escola Camoniana Brasileira. Entre seus nomes, podemos citar, entre outros, os de Emmanuel Pereira Filho, Leodegário Amarante de Azevedo Filho, Álvaro de Sá, Cleonice Berardinelli, além de Marina Machado Rodrigues, essa última, professora de Crítica Textual, lotada no Departamento de Ciências da Linguagem, do Instituto de Letras da UFF. 
Ainda acerca dessa prestigiosa Escola, vale destacar o papel de Emmanuel Pereira Filho para a proposição de um cânone mínimo ou básico da lírica camoniana, a partir da utilização do critério do tríplice testemunho quinhentista incontroverso de atribuição de autoria de poemas a Camões, já que havia e há sérios problemas de atribuição de autoria ao Poeta, assim como de estabelecimento e transmissão de textos da lírica camoniana. O continuador desse trabalho foi o Professor Leodegário A. de Azevedo Filho que julgou por bem flexibilizar o critério proposto por Pereira Filho.

Leodegário A. de Azevedo Filho, falecido em 2011, foi Presidente da Academia Brasileira de Filologia e entre suas publicações estão oito volumes da edição crítica da lírica de Camões, saídos pela Imprensa Nacional-Casa da Moeda de Portugal, publicação que teve, como texto de base, para seu estabelecimento, a tradição manuscrita da lírica camoniana, os famosos "livros de mão". Para informações mais detalhadas sobre a Escola Camoniana Brasileira, sugerimos a leitura de A Moderna Escola Camoniana Brasileira, de Marina Machado Rodrigues, continuadora dos trabalhos do saudoso Prof. Leodegário A. de Azevedo Filho ${ }^{1}$. Porém, este nosso artigo não versa sobre a lírica de Camões e sim sobre a presença de Camões no último capítulo de O crime do Padre Amaro. E o Camões lá presente está mais próximo do Camões épico de Os Lusíadas.

\section{A Presença de Camões em O Crime do Padre Amaro}

A primeira vez que Os Lusíadas foram publicados foi em 1572, num papel barato e, muito provavelmente, a edição era corrigida à medida que era impressa. Aliás, como disse Ana Virginia Pinheiro, chefe da Divisão de Obras Raras da Biblioteca Nacional (RJ), o maior valor daquele livro eram os versos ali estampados, e a Biblioteca Nacional (RJ) guarda, em seu acervo, um exemplar considerado, por grande parte dos pesquisadores e das pesquisadoras, como da primeira leva "das primeiras edições" de $O s$ Lusíadas, datadas de 1572.

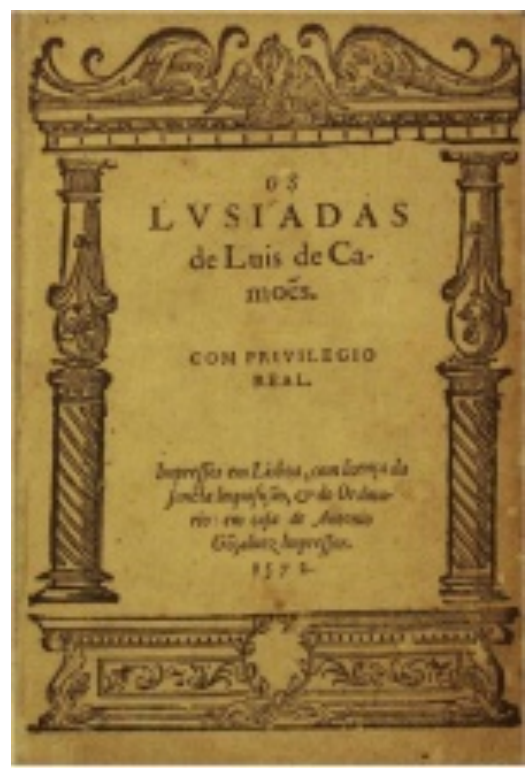

Figura1 - imagem retirada do site da FBN-RJ.

\footnotetext{
${ }^{1} \mathrm{O}$ trabalho de Maria Machado Rodrigues, a que se refere esta nota, está elencado nas referências deste artigo.
} 
Em relação aos exemplares diferentes da edição de 1572, é bastante conhecido o caso do pelicano com o pescoço virado para a esquerda e o do com o pescoço virado para a direita, na portada ilustrada na folha de rosto "das edições de 1572". Nesse sentido, cabe aqui lembrar das palavras de César Nardelli Cambraia, no capítulo intitulado A transmissão dos textos, de Introdução à crítica textual:

Embora tecnicamente os termos reimpressão e reedição se refiram a realidades distintas, verifica-se que, na prática, costumam ser utilizados indevidamente de forma intercambiável: para a crítica textual, porém, é capital diferenciar quando dois exemplares impressos pertencem a uma mesma edição (sendo frutos de mesma matriz) ou a edições diferentes (derivando de matrizes distintas). Sabe-se ainda, entretanto, que, durante o processo de impressão, eventualmente se faziam modificações na própria matriz, sem, no entanto, se destruírem os exemplares já impressos antes das referidas alterações: disso resulta a produção de exemplares, em uma mesma leva, que não são idênticos uns aos outros, caso em que se diz haver diferentes estados de uma mesma edição. $(2005, \text { p. } 75)^{2}$

Contudo, para a discussão acerca da primeira ou das primeiras edições de 1572 de Os Lusíadas, recomendamos a leitura de Uma, duas, quantas edições?, de José Luís Lisboa, que consta entre as referências deste nosso artigo.

Acerca da recepção de Os Lusíadas, tal obra foi citada e o nome de Camões referido por inúmeros escritores, escritoras, críticos e críticas literárias, filólogos e filólogas. Neste trabalho, destacamos, além dos citados anteriormente, os de: Montesquieu, Carolina Michaëlis de Vasconcellos, Machado de Assis, Eça de Queirós e, mais recentemente, o de Harold Bloom.

Para Harold Blomm, em Gênios, Eça de Queirós, que nasceu num dia 25 de novembro, no ano de 1845, seria um dos herdeiros de Camões, assim como Machado de Assis. E Eça, assim como Machado, além de serem considerados gênios por Bloom, participaram, cada um a seu modo, das homenagens a Camões, em 1880, terceiro centenário da morte do Poeta. Machado escreveu uma peça de teatro, encenada em 10 de Junho de 1880, cujo título foi retirado da estrofe 119, Canto III, de Os Lusíadas, "Tu só, tu, puro amor".

Eça, em 1880, publicou uma nova edição de $O$ crime do padre Amaro, em que, a cena que fecha o último capítulo é passada em frente à estátua de Camões, em Lisboa. Além disso, o autor de O primo Basílio e tantas outras obras se refere a um episódio da chamada história dos vencidos, até hoje, não usualmente citado, pelo menos aqui no Brasil: a Comuna de Paris, primeiro governo operário da história (18 de março a 28 de maio de 1871) que foi duramente reprimido. E, em maio de 1871, aconteceram as famosas Conferências Democráticas do Casino ou Cassino Lisbonense, que foram proibidas de terem prosseguimento pelo governo de Portugal à época, por meio de decreto público assinado pelo Marquês de Ávila e de Bolama, conforme A. Campos Matos (2011, p. 90). Tais conferências partiram de ideia de Antero de Quental e contaram com a participação de Eça de Queirós, entre outros. São também de 1871, As Farpas. Mas por que citamos 1880 como o da edição de $O$ crime do padre Amaro, já que o ano mais difundido da publicação daquele romance é o de 1875?

\footnotetext{
2 A palavra estados aparece em itálico no referido texto de César Nardelli Cambraia.
} 
É que o referido romance teve quatro edições em vida de Eça de Queirós, sendo que três delas são consideradas versões por Carlos Reis e Maria do Rosário Milheiro, na edição crítica que publicaram daquele romance, em 2000, ano do centenário do falecimento de Eça de Queirós.

Todas as quatro edições apresentam a cena que se passa nas proximidades da estátua de Camões? Todas elas fazem referência à Comuna de Paris? E por que apenas três delas podem ser consideradas versões? Vejamos, a primeira delas, a de 1875 , não foi autorizada por seu autor, que chega a chamá-la de borrão. Foi publicada na Revista Occidental, sob a responsabilidade de Jayme Baralha Reis e Antero de Quental e o autor já se encontrava em Newcastle.
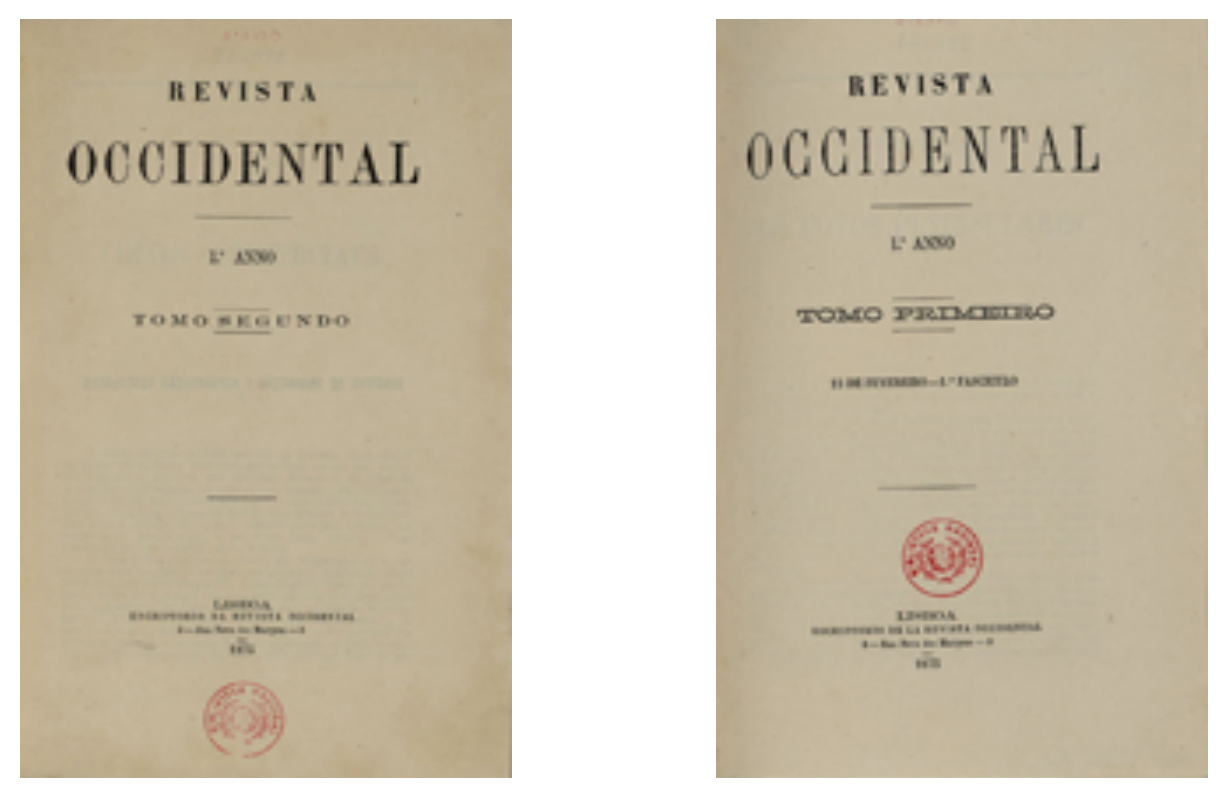

Figuras 2 e 3 - Capa das edições da Revista Occidental.

Desta edição, que tem ao todo 136 páginas, não consta a cena que se passa nas proximidades da estátua de Camões. A cena final daquela versão acontece junto às grades da Encarnação. Há referência a incêndios, à fuzilaria, em Paris, mas o nome Comuna de Paris não aparece. Além disso, aquele episódio histórico vem datado de maio de 1870.

À primeira edição de $O$ crime do padre Amaro, se seguiu uma espécie de pacto de silêncio da imprensa da época em relação àquele romance. Naquela edição de 1875 , o padre vivia um relacionamento amoroso com uma fiel da Igreja; os padres viviam de forma não condizente com a esperada. Além disso, o Padre Amaro teve um filho com Amélia. Amélia morre, mas, antes de Amélia morrer e, sem ela saber, o próprio padre Amaro mata o filho. Um escândalo para a época, como seria também para os dias de hoje.

Em 1876, é publicada a segunda edição do romance, a primeira em formato livro. Tal edição, que ao todo tem 362 páginas, foi paga pelo pai de Eça e conta com várias modificações autorais, inclusive, na estrutura do romance, daí ser considerada uma nova versão, a segunda. 


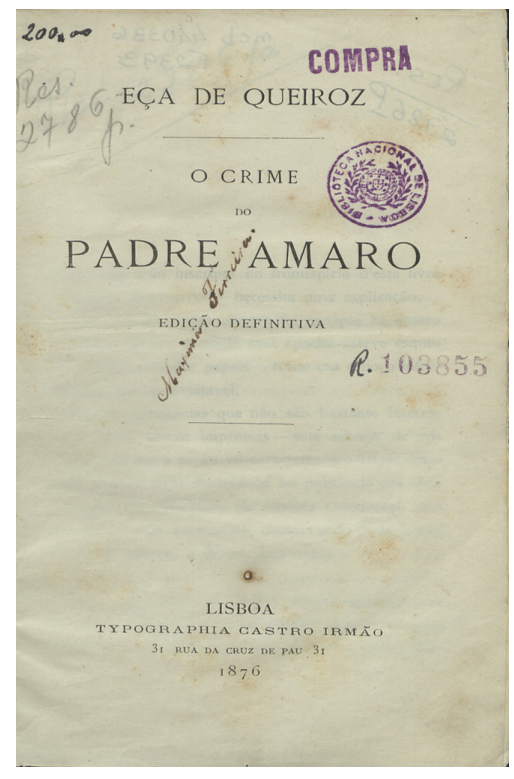

Figura 4 - Capa da edição de $O$ crime do padre Amaro, de 1876.

O autor também se encontrava em Newcastle. A informação da data, que abre o último capítulo, continua a ser "Nos fins de Maio de 1870". Contudo, há referência literal à Comuna:

[...] As palavras comunistas, Versailles, petróleo, diabos os levem, voltavam a cada momento. Com efeito, o telegrama chegado àquela hora perturbava, confundia os critérios.

Paris ardia!

A Comuna queimava a Cidade! [...] (Reis e Milheiro, 2000, p. 1018)

A cena se passa nas grades da Encarnação. Não há referência a Camões e o capítulo termina tal qual a edição de 1875 , porém não traz mais a nota que diz que a edição saiu sem as modificações que o autor pretendia fazer no texto. Inclusive, na folha de rosto da publicação de 1876, há a seguinte informação: edição definitiva. Porém no meio do caminho havia Machado de Assis. Sim, o nosso Machado de Assis, que em 1878, publica uma crítica aos romances O primo Basilio e O crime do padre Amaro.

Para Alberto Machado da Rosa (1979), tal crítica foi fundamental para que Eça fizesse uma verdadeira revolução naquele romance, que, em 1880, ano do terceiro centenário da morte de Camões, e também um momento de forte crise em Portugal (a monarquia estava sendo contestada, clamavam por democracia; ideias socialistas circulavam. Falavam também sobre a decadência de Portugal, sobre república, sobre questão social), sai numa nova edição que é uma outra versão, a terceira, de $O$ crime do padre Amaro, dessa vez com 674 páginas $^{3}$. E a data que abre o último capítulo daquela edição, o XXV, é, enfim, alterada para: "Nos fins de Maio de 1871 [...]" (Reis e Milheiro, 2000, p. 1019). A palavra Comuna é citada e é acrescentada a cena que se dá nas proximidades da estátua de Camões, em Lisboa, que é mantida, com pouquíssimas modificações, na última edição autorizada por Eça de Queirós e saída em vida desse autor, a de 1889.

\footnotetext{
3 Sobre quantidade de páginas das três primeiras edições de O crime do padre Amaro, v. Maria Filomena Mónica (2001, p. 157).
} 


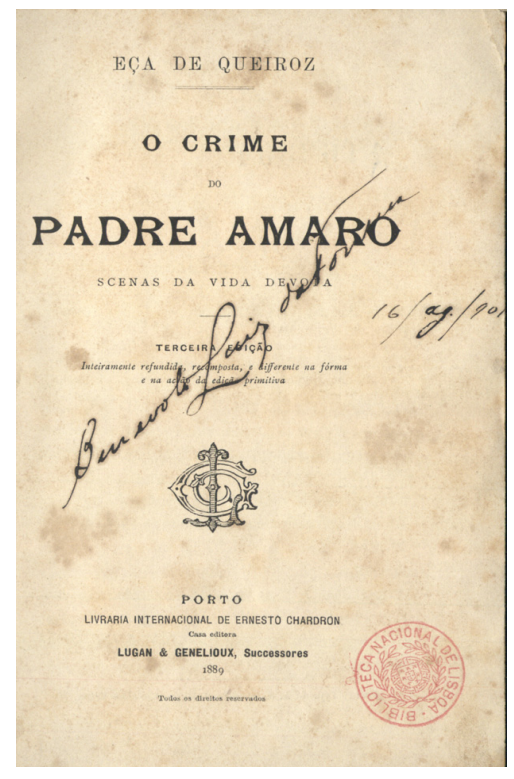

Figura 5 - Capa da edição de $O$ crime do padre Amaro, de 1876.

Do texto crítico da edição de 1889, preparado por Carlos Reis e Maria do Rosário Milheiro, e publicado na edição crítica de O crime do Padre Amaro, em 2000, é que retiramos os exemplos que, inclusive, dialogam e muito com o que vivemos hoje no Brasil. É um diálogo entre o conde de Ribamar, o padre Amaro e o cônego Dias:

[...] Ah! A imperatriz no trono de França, Pio Nono no trono de Roma, aí temos a democracia esmagada entre estas duas forças sublimes, e creiam Vossas Senhorias um homem que conhece a sua Europa e os elementos de que se compõe a sociedade moderna, creiam que depois deste exemplo da Comuna não se torna a ouvir falar de república, nem de questão social, nem de povo, nestes cem anos mais chegados!... [...]

- Deus Nosso Senhor o ouça, senhor conde, fez com unção o cônego.

Mas Amaro, radiante de se achar ali, numa praça de Lisboa, em conversação íntima com um ilustre, perguntou ainda, pondo nas palavras uma ansiedade de conservador assustado:

- E crê Vossa Excelência que essas ideias de república, de materialismo, se possam espalhar entre nós?

O conde riu: e dizia, caminhando entre os dois padres, até quase junto das grades que cercam a estátua de Luís de Camões:

- Não lhes dê isso cuidado, meus senhores, não lhes dê isso cuidado! É possível que haja aí um ou dois esturrados que se queixem, digam tolices sobre a decadência de Portugal, e que estamos num marasmo, e vamos caindo no embrutecimento, e isto assim não pode durar dez anos, etc., etc. Baboseiras!...

Tinha-se encostado quase às grades da estátua, e tomando uma atitude de confiança:

- A verdade, meus senhores, é que os estrangeiros invejam-nos... E o que vou lhes dizer não é para lisonjear a Vossas Senhorias: mas enquanto neste país houver sacerdotes respeitáveis como Vossas Senhorias, Portugal há-de manter com dignidade o seu lugar na Europa! Porque a fé, meus senhores, é a base da ordem!

- Sem dúvida, senhor conde, sem dúvida, disseram com força os dois sacerdotes.

-Senão, vejam Vossas Senhorias isto! Que paz, que animação, que prosperidade! [...] (Reis e Milheiro, 2000, p. 1033).

E então há um desfilar, pela voz do narrador, de imagens, de figuras que ilustram o inverso do que foi dito pelo conde, num cenário de decadência, e esse desfilar se dará diante da estátua de Camões, que segura, junto ao coração, Os Lusíadas. 


\section{CONSIDERAÇÕES FINAIS}

O romance termina com um tom de quase total desesperança. Digo quase total, talvez por ser otimista. Mas, a partir da leitura da descrição do monumento em homenagem a Camões, presente nas páginas escritas por Eça de Queirós, podemos reparar que o Poeta está "com a epopeia sobre o coração" e "cercado dos cronistas e dos poetas heroicos da antiga pátria [...]" (Reis e Milheiro, 2000, p. 1035). E o romance termina com: “[...] - pátria para sempre passada, memória quase perdida!", seguida, na outra linha da data Outubro de 1878 - Outubro de 1879 (Reis e Milheiro, 2000, p. 1035).

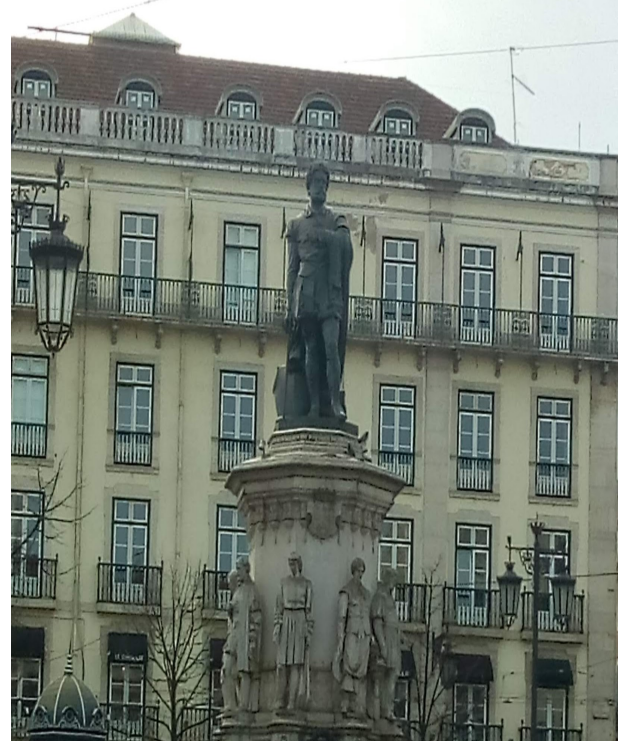

Figura 6 - Foto tirada pela autora deste artigo em 8 de março de 2020.

A memória está quase perdida, mas o Poeta continua a contar-nos, com a epopeia sobre o coração, e a nos possibilitar a recordação, ou seja, a trazer de volta aos nossos corações e mentes, parte da história de Portugal e também a fazer críticas, apesar da voz enrouquecida, a parte dessa história.

Camões e Eça, além de inovarem, transformarem e divulgarem a língua portuguesa e a literatura em língua portuguesa, tiveram a coragem de construir histórias que trazem à visibilidade da folha publicada parte do que estava relegado ao esquecimento, e a coragem é uma espécie de salvação, já dizia Platão (1996, p. 179). Talvez, uma salvação também para nós, se não recusarmos o apelo que a história de todas e de todos, que lutaram por um mundo justo, nos fazem hoje.

Estamos em 2020, num Brasil embrutecido, vilipendiado, ferido quase de morte. Cabe a nós, termos coragem e espero, sinceramente, que tenhamos, pois, se não tivermos citando Benjamin (2012, p. 244), "tampouco os mortos estarão em segurança se o inimigo vencer. E esse inimigo não tem cessado de vencer." Porém, como disse Simone de Beauvoir, "o presente, não é o passado em potência, é o momento da escolha e da ação". 


\section{REFERÊNCIAS}

Beauvouir S. O pensador. www.pensador.com. [citado 17 jul. 2020]. Disponível em: https://www.pensador.com/frase/ODgwNw.

Benjamin W. Sobre o conceito da história. In: Benjamin, W. Magia e técnica, arte e política. Ensaios sobre literatura e história da cultura. Trad. Sérgio Paulo Rouanet. $8^{a}$ ed. São Paulo: Brasiliense; 2012. p. 241-252.

Bloch M. Apologia da história ou o ofício de historiador. Trad. André Telles. Rio de Janeiro: Zahar; 2001.

Bloom H. Gênio. Os 100 autores mais criativos da história da literatura. Trad. José Roberto O’Shea. Rio de Janeiro: Objetiva; 2003.

Cambraia CN. Introdução à crítica textual. São Paulo: Martins Fontes; 2005.

Camões LV de. Os Lusíadas. Edição comentada por Francisco da Silveira Bueno. São Paulo: Saraiva; 1960. (Vols. I e II).

Lisboa JL. Uma, duas, quantas edições?. Cultura [Online], 2014;33:97-108. [citado 17 jul. 2020].

Disponível em: http://journals.openedition.org/cultura/2378.

Matos AC. Eça de Queirós: uma biografia. Cotia/Campinas: Ateliê Editorial/Editora da Unicamp; 2014.

Mónica MF. Eça: vida e obra de José Maria Eça de Queirós. Rio de Janeiro: Record; 2001,

Platão. A república. Introdução, tradução e notas Maria Helena da Rocha Pereira. 8 ed. Lisboa: Fundação Calouste Gulbenkian; 1996.

Queiroz JME de. O crime do padre Amaro. Biblioteca Digital da Biblioteca Nacional de Portugal: Lisboa; 1876.

Reis C, Milheiro M do R, editores. Edição crítica das obras de Eça de Queirós. O crime do padre Amaro. Lisboa: Imprensa Nacional - Casa da Moeda; 2000.

Rodrigues MM. A moderna escola camoniana brasileira. Congresso Internacional de Língua Portuguesa, Filosofia e Literaturas de Língua Portuguesa, 2007. Anais. 2007:31-41. [citado 16 jul. 2020]. Disponível em: http://www.filologia.org.br/vii_jnf/tex/31-41.pdf.

Rosa AM da. Eça, discípulo de Machado? Um estudo sobre Eça de Queirós. 2 ed. revista. Lisboa/São Paulo: Presença/Martins Fontes; 1979.

Souza J. A elite do atraso. Da escravidão à lava jato. Rio de Janeiro: Leya; 2017. 